\title{
PHYSICAL PROPERTIES ANALYSIS OF ENVIRONMENTALLY FRIENDLY REFRIGERANT ON THE CONVECTIVE HEAT TRANSFER COEFFICIENT
}

\author{
Jeri Tangalajuk SIANG ${ }^{(1 D}$, Jeremias M LEDA ${ }^{1}$, Firdaus CHAIRUDDIN ${ }^{1}$
}

DOI: 10.21163/GT_2020.151.30

\begin{abstract}
:
The negative impacts of synthetic refrigerant on the environment are ozone depletion and global warming. In spite of all the new refrigerants has no ozone depletion potential (ODP), only the existing refrigerant R22 has ODP as 0.055 , however, the global warming potential of the new refrigerants are high. Therefore the use of environmentally friendly refrigerants is a must. Propane (R290) and isobutene (R600a) are environmentally friendly refrigerants as the refrigerants have no ODP and negligible GWP. R290 is more efficiently than R22 because R290 has higher COP. One should be noted of two refrigerants, R290 and R600a is their flammability. Therefore, the amount of R290 or R600a should be minimized in refrigeration or air conditioning system. This research is conducted experimentally and theoretically comparing the effect of physical properties on the heat transfer process of the low mass of R290 and R290 - R600a blends. An increase in vapor quality decreases the convective heat transfer coefficient. This is due to the decrease in thermal conductivity and specific heat of the refrigerant with an increase in the vapor quality. R290 has the highest convective heat transfer coefficient while $60 \%$ R290 - 40\%R600a blend has the lowest convective heat transfer coefficient.
\end{abstract}

Key-words: Synthetic refrigerant, environmentally friendly refrigerant, $Q D P, G W P$.

\section{RESEARCH BACKGROUND}

The use of synthetic refrigerants which have negative impacts on the environment has been decreased. The significant step is there is no production on ozone depletion refrigerant. However, the used of this kind of refrigerant still can be found to utilize the air conditioning system. R22 is the ozone depletion refrigerant with ozone depletion potential (ODP) index as 0.055 which is still in the R22 air conditioning system. The common synthetic refrigerant such as R134a, R410A, R32 and R407C are free of ODP but still have global warming potential (GWP). Global warming potential is the potential of a substance in trapping greenhouse heat compare to CO2. The GWP of R134a, R410A, R32, and R407C refrigerants are 1432, 2100, 650 and 1980 respectively (Padmanabhan and Palanisamy, 2013; Padalkar et al., 2014; Bolaji and Huan, 2013). Refrigerant life in the atmosphere is also an important thing. When the refrigerant remains exist in the atmosphere, the negative impact of the refrigerant is also with the refrigerant. One of negative impacts of global warming is heat wave (Suparta and Yatim, 2019; Bocancea, 2018; Esmailnejad, 2016). Suparta and Yatim, 2019 found that the heat wave has negative impact on plantation and human being healthy. Bocancea (2018) analyzes the heat wave in

\footnotetext{
${ }^{1}$ Univeras Atma Jaya Makassar, Makassar, Indonesia, jeri_siang@lecturer.uajm.ac.id; je.leda@uajm.ac.id ; firdauschaeruddin@gmail.com
} 
Romania and found that the duration of heat wave in Romania increases in a period of 1961 - 2017. Esmailnejad (2016) found that heat wave occurs in part of Iran several days in a year. Global warming also contributes to extreme rainfalls in Indonesia. Even though there is much water in the rainy season, but the quality of the water is at a low level due to waterflood. Dwianika et al (2020 stated that it is important to manage the water resources to avoid the conflicts which are from water source problems. Therefore, the researchers need to find the way to reduce the global warming potential.

As the synthetic refrigerants used in the refrigeration and air conditioning system still have the GWP, the research on the environmentally friendly refrigerant continuous to carry out. The environmentally friendly refrigerant substantively known a long time ago, however, as the synthetic refrigerants proposed the better performance, the use of environmentally friendly refrigerants are not used. Ammoniac is an environmentally friendly refrigerant. The drawback of the ammoniac is corrosively, therefore ammoniac needs a specific un-corrosive design system. The next environmentally friendly refrigerant is $\mathrm{CO}_{2}$. This type of refrigerant is not familiar in refrigeration because $\mathrm{CO}_{2}$ needs highpressure air conditioning design. Another environmentally friendly refrigerant is the hydrocarbon. Hydrocarbon has an advantage among other environmentally friendly refrigerants. Propane (R290) and isobutene (R600a) are hydrocarbons which commonly used in the refrigeration system. Hydrocarbon (propane/R290) has similar operational pressure with R22. This advantage brings the R290 into the research to be the future refrigerant. The only drawback of the R290 is its flammability. Hydrocarbon has no ODP and negligible GWP (3). The lifetime of hydrocarbon in the atmosphere is one of its advantages. Hydrocarbon lifetime is 3 years, therefore the effect of hydrocarbon on the environment only in 3 years. Another hydrocarbon that already used in the refrigeration system is isobutene (R600a). R600a is popular in the refrigeration area. Refrigerator with R600a as its refrigerant is already in the market. R600a and R290 have the same ODP, GWP and atmosphere lifetime.

As the hydrocarbons are environmentally friendly refrigerant, these refrigerants become popular today. It is easy to find research on hydrocarbon. Previous researches show that R290 has a better COP compared to R22. The cooling capacity of R290 is slightly lower than its R22 (Park et al., 2007). Siang and Sharifian, 2017 found that the cooling capacity of R290 increases gradually from $-20 \%$ undercharged - $+30 \%$ overcharged.

As R290 is a flammable substance, the safety should be noted. Previous researches indicated that comparing to R22, the mass of R290 in the same system with R22 is about $40 \%-50 \%$ mass for the COP and cooling capacity as explained previously (Gartshore et al., 1995). The use of R290 as refrigerant is in the small air condition system. This is due to the regulation of safety. When the mass of R290 lower than $40 \%$ of R22 mass in the system, the evaporator pipe easily covered by an ice layer. This is caused by the low pressure in the evaporator. The ice layer appears at the evaporator pipe because the temperature of R290 at that pressure is below the frosting temperature of the water. Siang and Sharifian, 2018 stated that increasing airspeed over the evaporator decreases the risk of frosting development around the evaporator pipe.

The research of comparison of the performance of R22 at normal charge with R290 at low charge $32 \%$ of R22 mass has been carried out with the result: COP of R290 is lower than the COP of R22. The cooling capacity of R290 is lower than the cooling capacity of 
$\mathrm{R} 22$ at low and moderate speed of air over the evaporator, at $2.0 \mathrm{~m} / \mathrm{s}$, the cooling capacity of R290 is slightly lower than the cooling capacity of R22 (Siang et al., 2019a). The low pressure of R290 at a low charge has been studied in previous research. COP of R290 R600a blend is slightly higher than R290 but the cooling capacity of this mixture is slightly lower than R290 (Siang et al., 2019b).

The present research aims to analyze the effect of the physical properties of R290 R600a blend on the evaporation convective heat transfer coefficient compared to R290. Most of the previous researches on evaporation and condensation heat transfer coefficient found that the convective heat transfer coefficient increases with increasing the vapor quality (Park et al., 2008; Lee at al., 2005; Lee at al., 2006). However, Wang et al., 2013 have a different result. In their research, they found that the convective heat transfer coefficient may increase, remain constant or decreases. It depends on the boiling number and liquid and vapor density ratio of the refrigerant (Kandlikar and Steinke, 2002).

\section{METHODOLOGY OF THE RESEARCH}

The first step of the present research is experimentally collecting data of $120 \mathrm{~g} \mathrm{R} 290$ mass in $3 / 4 \mathrm{PK}$ window air conditioning. The air conditioning has been modified to be an experiment apparatus can be seen in Fig. 1. Data collecting rom the experiment work are inlet and outlet temperature of evaporator and condenser, inlet and outlet pressure of evaporator and condenser, wind speed at inlet of the evaporator, temperature of the room and electrical power. After collecting data experiment, the COP and cooling capacity are calculated. Thermal conductivity, specific heat and viscosity are based on the saturation temperature of the evaporator. The last step of the present research is theoretically calculated the performance of R290 - R600a blend, physical properties and evaporation heat transfer coefficient of R290 - R600a blend.

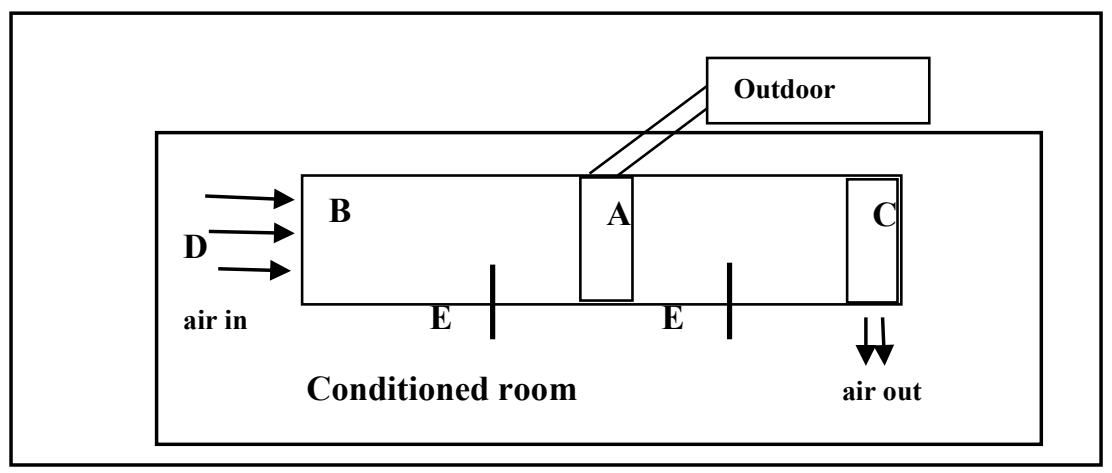
A : Evaporator
B : Wind tunnel
C : Blower
D : Anemometer
E : Bar thermometer

Fig. 1. Schematic diagram of experimental apparatus.

The speed of air over the evaporator was at $0.5 \mathrm{~m} / \mathrm{s}, 1.0 \mathrm{~m} / \mathrm{s}, 1.5 \mathrm{~m} / \mathrm{s}$ and $2.0 \mathrm{~m} / \mathrm{s}$. Speed of air was recorded by fan anemometer with accuracy $\pm 5 \%$. 
The evaporator pressure was assumed constant as well as condenser pressure and was recorded using bourdon pressure gauge with least count of $1^{\circ} \mathrm{C}$. Inlet temperature of evaporator was not recorded as it was the saturation temperature. Outlet temperature of evaporator, inlet and outlet temperature of condenser was recorded by thermocouple with least count of $1^{\circ} \mathrm{C}$. Inlet and outlet air temperature over the evaporator, room temperature were recorded by $1^{\circ} \mathrm{C}$ least count bar thermometer. Electric current was measured using power clamp with $\pm 2.0 \%$. The properties of the refrigerant was found by using REFPROP 6.02

Reynolds number, Nusselt number, Prandtl number and convective heat transfer coefficient were calculated with the formula:

$$
\begin{aligned}
& R e=\frac{4 m_{r}}{\pi d \mu_{r}} \\
& \operatorname{Pr}=\frac{\mu c_{p}}{k} \\
& N u_{D}=0.023 \operatorname{Re}_{D}^{4 / 5} \operatorname{Pr}^{0.4} \\
& h=\frac{k N u_{D}}{d}
\end{aligned}
$$

Convective heat transfer coefficient can be expressed as Equation (5) when Eq. (1) and (2) is put into Eq. (3)

$$
h=0.0697\left(\frac{m_{r}}{\pi}\right)^{0.8}\left(\frac{C p}{\mu_{r}}\right)^{0.4}\left(\frac{k}{d^{3}}\right)^{0.6}
$$

\section{RESULTS AND DISCUSSION}

Table 1 shows that the highest cooling capacity is R290, and the lowest cooling capacity is $60 \% \mathrm{R} 290-40 \% \mathrm{R} 600 \mathrm{a}$. The highest COP of the system is with $60 \% \mathrm{R} 290-$ $40 \%$ R600a blend as 5.019 while the lowest COP is R290 as 4.544 Physical properties of the refrigerant at the condition shown in table 1 are presented in the next Figures.

Table 1.

Performance of the refrigerants in the present research.

\begin{tabular}{lllllllll}
\hline Ref & $\begin{array}{l}\mathrm{P}_{\text {evap }} \\
(\mathrm{MPa})\end{array}$ & $\begin{array}{l}\mathrm{P}_{\text {cond }} \\
(\mathrm{MPa})\end{array}$ & $\begin{array}{l}\mathrm{T}_{1} \\
\left({ }^{\circ} \mathrm{C}\right)\end{array}$ & $\begin{array}{l}\mathrm{T}_{2} \\
\left({ }^{\circ} \mathrm{C}\right)\end{array}$ & $\begin{array}{l}\mathrm{T}_{3} \\
\left({ }^{\circ} \mathrm{C}\right)\end{array}$ & $\begin{array}{l}\mathrm{T}_{4} \\
\left({ }^{\circ} \mathrm{C}\right)\end{array}$ & $\begin{array}{l}\text { Cooling } \\
(\mathrm{Kw})\end{array}$ & $\mathrm{COP}$ \\
\hline $\mathrm{A}$ & 0,339 & 1,239 & 4,971 & 56.000 & 34.000 & $-10,522$ & 0,966 & 4,544 \\
$\mathrm{~B}$ & 0,339 & 1,239 & 5,652 & 56.000 & 34.000 & $-8,336$ & 0,963 & 4,663 \\
$\mathrm{C}$ & 0,339 & 1,239 & 6,295 & 56.000 & 34.000 & $-5,962$ & 0,959 & 4,789 \\
$\mathrm{D}$ & 0,339 & 1,239 & 6,894 & 56.000 & 34.000 & $-3,378$ & 0,954 & 4,924 \\
$\mathrm{E}$ & 0,339 & 1,239 & 7,085 & 56.000 & 34.000 & $-0,566$ & 0,948 & 5,019 \\
\hline
\end{tabular}

Fig. 2 shows that the specific heat of the refrigerant decreases as the vapor quality decreases. The most decrease in specific heat is R290 as $17.6 \%$ and the least decrease is $60 \%$ R290 - 40\%R600a blend as $15.8 \%$. 


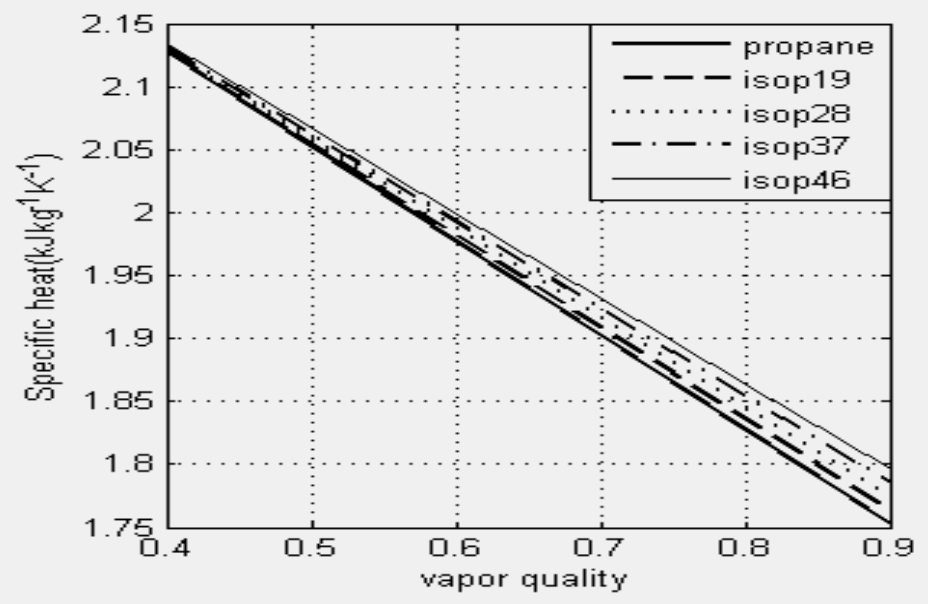

Fig. 2. Specific heat.

Figure 3 shows the change in the thermal conductivity of the refrigerant versus vapor quality. 60\%R290 - 40\%R600a has the highest thermal conductivity while R290 has the lowest thermal conductivity. On the other hand, the thermal conductivity of R290 decreases most $66.6 \%$ compared to other refrigerants. The refrigerant with the least decrease in thermal conductivity is $60 \% \mathrm{R} 290-40 \% \mathrm{R} 600 \mathrm{a}$ blend as $65.0 \%$.

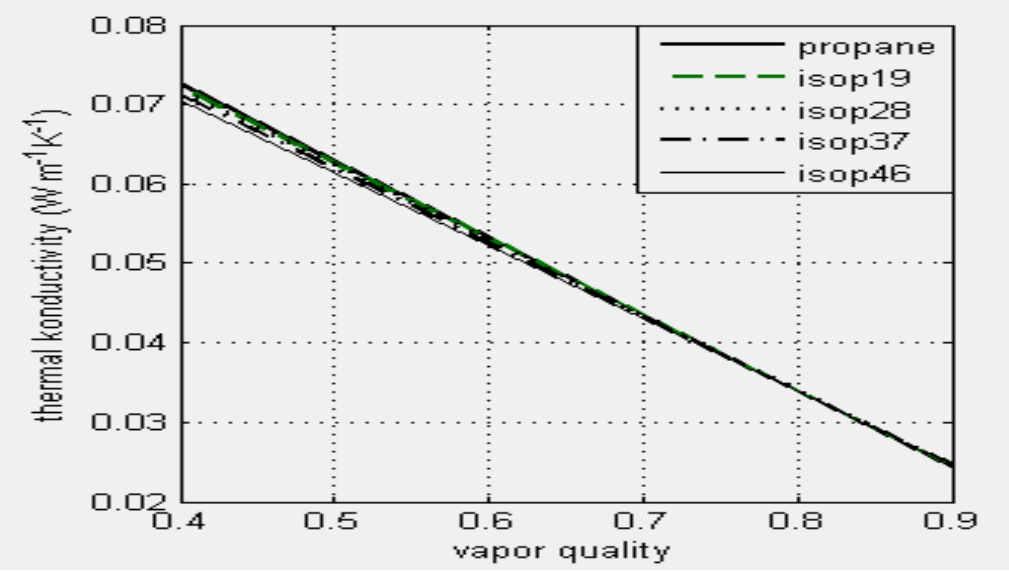

Fig. 3. Thermal conductivity.

The change of viscosity of the refrigerant with vapor quality is shown in Fig. 4. The figure shows the $60 \%$ R290 - 40\%R600a blend has the highest among the refrigerants in this research and also decreases most in $76.9 \%$ as the vapor quality increases. Even though R290 has the lowest viscosity but decreases the least in $76.2 \%$ compared to other 
refrigerants. As a result, the viscosities of all refrigerants in this research have nearly similar at vapor quality of 0.9 .

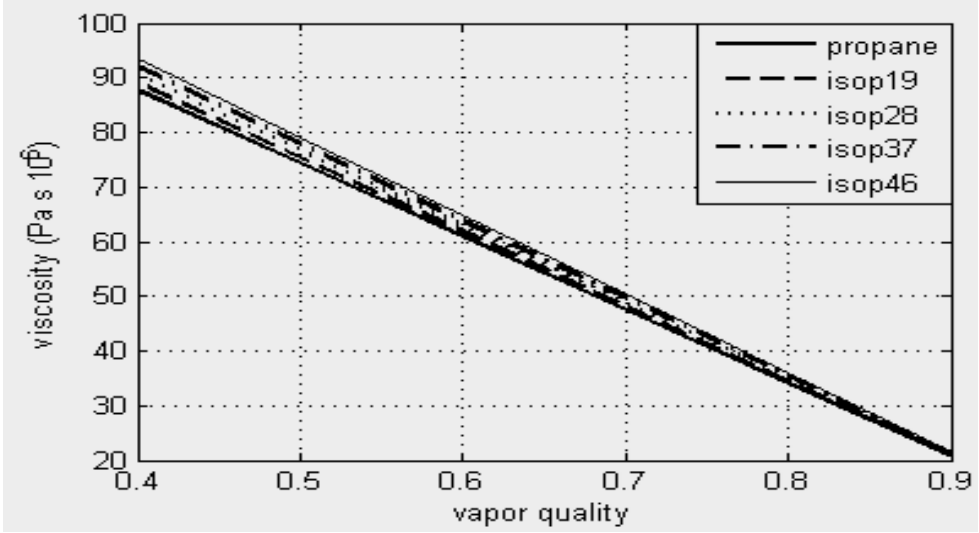

Fig. 4. Viscosity.

The comparison of Reynolds number of R290 and the variation of R290 - R600a blend is presented in Fig. 5. The figure shows the change of Reynolds number $(\mathrm{Re})$ in the range of $0.4-0.9$ vapor quality. There is a similar trend of Re number increases with R290 has the highest Re number, 60\%R290 - 40\%R600a blend has the lowest Re number. All the refrigerants increase by around $300 \%$ when the vapor quality increases from 0.4 to 0.9 . The viscosity of the refrigerant has an important role in the change of the value of Re number. Re value increases with decreases in viscosity.

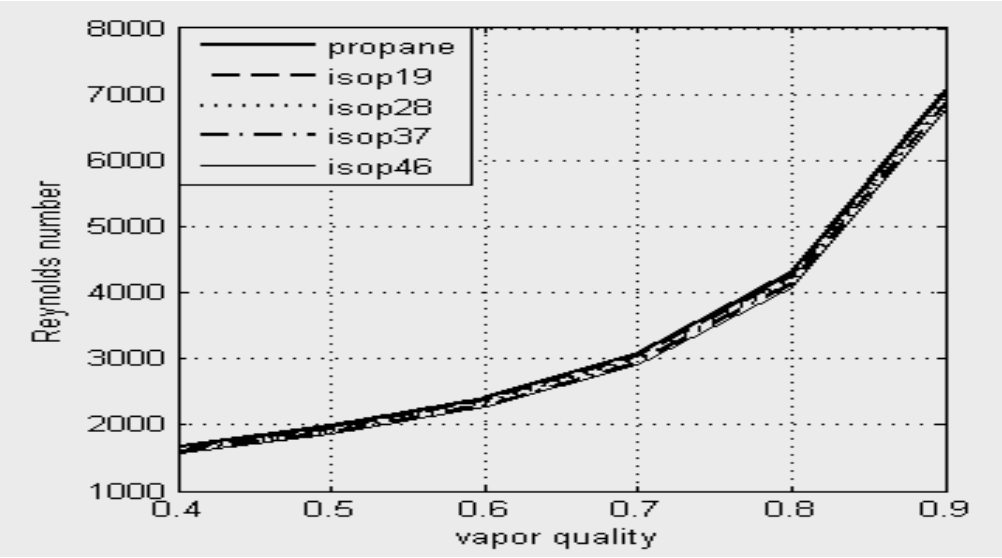

Fig. 5. Reynolds number.

Fig. 6 shows the change of Pr number along the $0.4-0.9$ vapor quality. The Figure shows that $60 \%$ R290 - 40\%R600a blend has the highest value while R290 has the lowest Pr number. The highest percentage of Pr decreasing is R290 as $44.5 \%$ while the lowest decrease in Pr number is 60\%R290 - 40\%R600a blend as 41.3\%. Thermal conductivity, 
viscosity and specific heat influence the value of Pr number. Thermal conductivity and viscosity are directly proportional to $\operatorname{Pr}$ number, while specific heat is inversely proportional to Pr number.

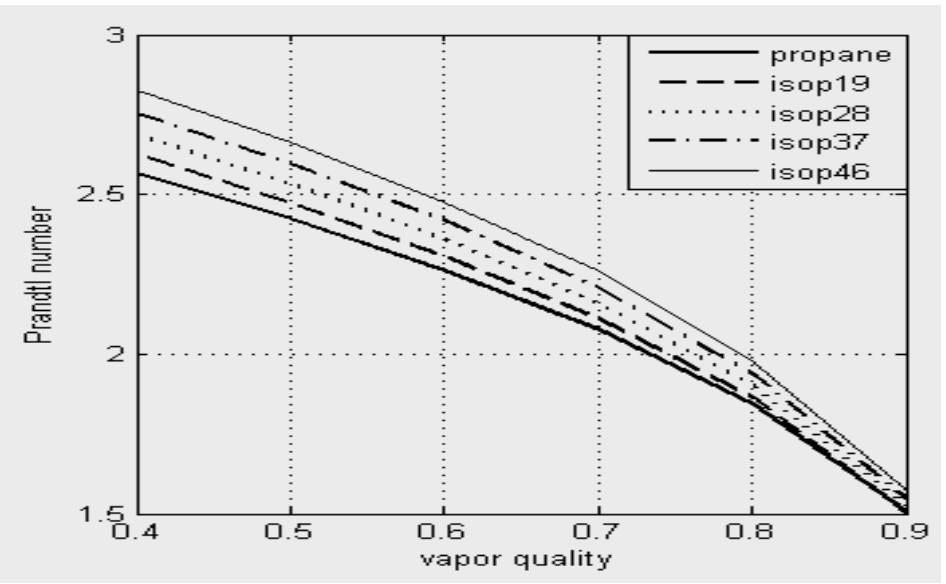

Fig. 6. Prandtl number.

The next important variable that affects the heat transfer coefficient is the Nusselt number. The variation of Nusselt number of the refrigerants is presented in Fig. 7. The figure shows that the trend of the $\mathrm{Nu}$ number of refrigerants in this research nearly similar throughout with the vapor quality change. Similar to the Re number, the refrigerants in this research have the same increasing trend. All the Re number of the refrigerants increase around $155 \%$.

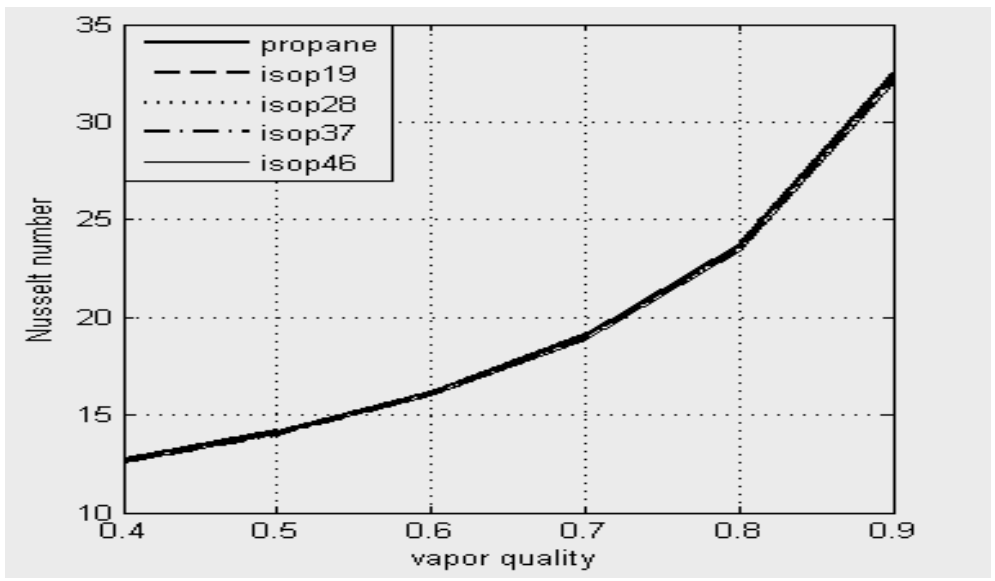

Fig. 7. Nusselt number.

In Fig. 8, the change in the heat transfer coefficient of the refrigerants is presented. Generally, the heat transfer coefficients of the refrigerants decrease by an increase in vapor 
quality except for the blend of $40 \% \mathrm{R} 600 \mathrm{a}-60 \% \mathrm{R} 290$ at vapor quality of 0.8 to 0.9 . The convective heat transfer coefficient is indicated to be increasing.

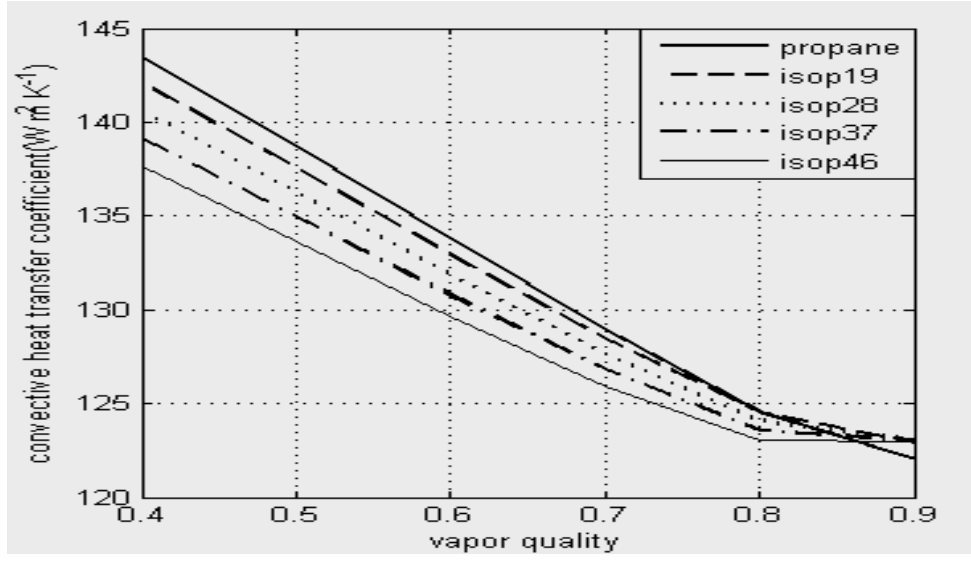

Fig. 8. Convective heat transfer coefficient.

Fig. 8 indicates that R290 has the highest value of convective heat transfer coefficient (h) at a low vapor quality of 0.4 , and the lowest h is $60 \%$ R290 $-40 \%$ R600a blend. But at 0.9 vapor quality, h of R290 is the lowest while all four blends $(60 \% \mathrm{R} 290-40 \% \mathrm{R} 600 \mathrm{a}$, $70 \%$ R290 - 30\%R600a, 80\%R290 - 20\%R600a and 90\%R290 - 10\%R600a) have the similar value of $\mathrm{h}$. The $\mathrm{h}$ is directly proportional to $\mathrm{Cp}^{0.4}$ and $\mathrm{k}^{0.6}$ while $\mathrm{h}$ is inversely proportional to $\mu^{0.4}$.

Table 2 shows the ratio of fluid density to the vapor density of the refrigerants. Table 2 shows that R290 has the highest density ratio. An increase in the percentage of R600a in the R290 - R600a blend brings to a higher density ratio.

Table 2.

Ratio of fluid density to vapor density of refrigerant.

\begin{tabular}{lccc}
\hline Refrigerant & $\rho_{\text {liquid }}$ & $\rho_{\text {vapor }}$ & $\rho_{\text {liquid }} / \rho_{\text {vapor }}$ \\
\hline R290 & 542,900 & 7,513 & 72,261 \\
$90 \% R 290-10 \% R 600 a$ & 545,149 & 7,555 & 72,158 \\
$80 \% R 290-20 \% R 600 a$ & 547,303 & 7,625 & 71,780 \\
$70 \% R 290-30 \% R 600 a$ & 549,292 & 7,717 & 71,184 \\
$60 \% R 290-40 \%$ R600a & 551,07 & 7,827 & 70,406 \\
\hline
\end{tabular}

\section{CONCLUSION}

The effect of the physical properties of the refrigerant on the convection heat transfer coefficient directly proportional to thermal conductivity and specific heat of the refrigerant. The effect of viscosity can be negligible in the present research. From Eq. 5, the convective heat transfer coefficient increases while the viscosity decreases. 
In fact, the heat transfer coefficient remains decreases although the viscosity decreases. It can be caused by the power of viscosity is 0.4 but the power of thermal conductivity is 0.6 and (Eq. 5). Also, the combination of decreases in thermal conductivity and specific heat is more powerful compared to the decreases in viscosity. The ratio of the density of the refrigerants in Table 2 is around $70-73$. Compared to Kandlikar (1991), it partially agrees with his work. In Kandlikar's work, the heat transfer increases with vapor quality at 1000 density ratio but decreases with vapor quality when the density ratio is 10 . It is important to note that by converting the synthetic refrigerant with R290 and R600a will decrease the risk of global warming. This is because R290 and R600a have low GWP with short amospheric life time.

\section{R E F E R E N C E S}

Bocancea, R.S. (2018) Heat waves frequency. A study case of Iasi city, Romania (19612016). Geographia Technica, 13(1), 10-19.

Bolaji B. O. \& Huan Z. (2013) Ozone depletion and global warming: case for the use of natural refrigerant - a review. Renewable and Sustainable Energy Review, 18, 49 - 54.

Dwianika, A., Murwaningsari, E. and Suparta, W. (2020) Analysis of water awareness, accountability, and governance to improve sustainability of firm's performance in urban areas. Geographia Technica, 15 (1), 32 - 42.

Gartshore, J. 1995 Refrigeration appliances using hydrocarbon refrigerants: manual for safe design, manufacturing, servicing and drop-in conversion of commercial and domestic refrigeration appliances. An ECOFRIG.

Kandlikar S. G. \& Steinke M. E. 2002 flow boiling heat transfer coefficient in mini channels correlation and trend. proceeding of 12th International Heat Transfer Conference. Grenoble, France.

Lee H. S., Yoon J. I., Kim J. D. \& Bansal P. K. (2006) Condensing heat transfer and pressure drop characteristics of hydrocarbon refrigerants. International Journal of Heat and Mass Transfer, 49, $1922-1927$.

Lee H. S., Yoon J. I., Kim J. D. \& Bansal P. K. (2005) Evaporating heat transfer and pressure drop of hydrocarbon refrigerants in 9.52 and $12.70 \mathrm{~mm}$ smooth tube. International Journal of Heat and Mass Transfer, 48, 2351 - 2359.

Morteza E. (2016) The spatial analysis of heat waves in South East of Iran a case study: Sistan and Baluchestan Province. Geographia Technica, 11 (2), 50 - 60.

Padalkar A. S., Mali K. V. \& Devotta S. (2014) Simulated and experimental performance of split package air conditioner using refrigerant HC - 290 as Substitute for HCFC - 22. Applied Thermal Engineering, 62, 277 - 284.

Padmanabhan V. M. V., \& Palanisamy S. K. (2013) Exergy efficiency and irreversibility comparison of R22, R134a, R290 and R407C to replace R22 in an air conditioning system. Journal of Mechanical Science and Technology. 27 (3), 917 - 926.

Park K., Jung D., and Seo T. (2008) Flow condensation heat transfer characteristics of hydrocarbon refrigerants and dimethyl ether inside a horizontal plain tube. International Journal of Multiphase Flow, 34, $628-635$.

Park K., Seo T., \& Jung D. (2007) Performance of alternative refrigerants for residential airconditioning applications. Applied Energy, 84, 985 - 991. 
Siang J. T., Leda J. L., \& Chairuddin, F. (2019) The performance of the engine cooling room with a minimum mass of propane refrigerant. Proceeding of the Seminar Riset dan Teknologi 2019 (SEMRESTEK 2019), Jakarta, Indonesia.

Siang J. T., Leda J. M., \& Chairuddin F. (2019) The comparison of R290 and mixture of R600a with R290 on evaporator temperature at low charge. Proceeding of the $5^{\text {th }}$ International Conference on Science and Technology $\left(5^{\text {th }}\right.$ ICST), IEEE, Yogyakarta, Indonesia.

Siang J. T. \& Sharifian, A. (2018) Effect of inlet pressure, size and wind speed of an evaporator on amount of refrigerant charge and performance of a portable propane air conditioner. IEEE, Yogyakarta, Indonesia.

Siang J. T. \& Sharifian, A. (2017) Performance of a single-duct portable propane air conditioning system under different refrigerant charge levels. Heat Transfer-Asian Research, 46 (8), 1 - 16.

Suparta, W. \& Yatim A. N. M. (2019) Characterization of heat waves: a case study for Peninsular Malaysia. Geographia Technica, 14 (2), 146 - 155.

Wang, S., Gong M. Q., Chen, F. G., Sun, Z. H. \& Wu, J. F. (2013) Two phase heat transfer and pressure drop of propane during saturated flow boiling inside a horizontal tube. International Journal of Refrigeration, 41, pp $200-209$. 